\title{
Balanced reading instruction for improving teachers' instruction of reading comprehension to Runyankole-English bilingual children
}

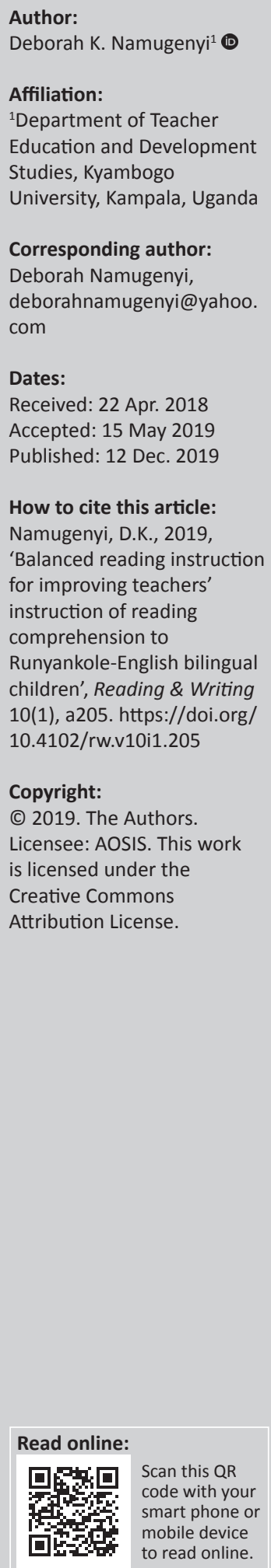

Background: Reading comprehension is a challenge among bilingual children. Reading comprehension difficulties are likely to be attributed to the strategies teachers use during their instruction of reading to these children.

Objectives: In light of this, the purpose of this study was to establish the effectiveness of a balanced reading instruction programme in empowering teachers with strategies for improving their instruction of reading comprehension in both the native language and English.

Method: Qualitative participatory action research was used in the design and implementation of the balanced reading instruction programme. Participants were four Grade 3 teachers as direct participants and 40 children as indirect participants in 'NKPS' (pseudonym) primary school, Mbarara Municipality, Uganda. Data was collected through focus group interviews, observation, document analysis, and a researcher's reflective journal. Data was collected in accordance to the participatory action research cyclic process through which the programme was implemented.

Results: Results showed that teachers' participation in the balanced reading instruction programme empowered them with better strategies such as phonics instruction and formulating carefully graded questions on different texts, to teach reading comprehension first in children's native language (Runyankole) and then in English.

Conclusion: The study being action-oriented and working in collaboration with teachers in one single school offers its conclusions from the findings to be transferred to similar contexts. It is recommended that a large-scale intervention should be conducted for improving teachers' instruction of reading comprehension to bilingual children.

Keywords: Balanced reading instruction; reading comprehension; bilingual children; Runyankole; participatory action research.

\section{Introduction}

The native language and English are taught concurrently to Ugandan children aged 6-8 years in lower primary classes (Grade 1-3). This is done to ensure that the literacy skills attained in the native language will help children learn English as a second language (National Curriculum Development Centre, NCDC 2007). The instruction of the two languages is in accordance with the language policy of Uganda that states:

Community languages/local languages should be used as a medium of instruction from primary one to primary four (6-9 years), with English being taught as a subject in these classes. Thereafter, from primary five to primary seven (10-12 years), English should be used as a medium of instruction and taught as a subject as well. The community languages should be taught as a subject in these classes. English language would continue to be used as a medium of instruction at the levels of education in Uganda (secondary schools and tertiary institutions. (Uganda Government 1992:15-17)

Thus, the lower primary (Grade 1 to 3) school curriculum is designed such that teachers ought to engage children in various reading activities when teaching the native language and English. These activities include associating words with pictures, completing pictures and words, reading and completing sentences, reading and comprehending different texts, reading and describing different texts (Garton \& Pratt 1998; NCDC 2007). It is through these activities that children are expected to acquire different literacy skills to excel in their academic subjects at school, as well as for lifelong learning. Such skills include decoding skills, comprehension skills and skills for critical analysis of texts (Barrat-Pugh \& Rohl 2000). 
In spite of the teachers' engagement with children in different reading activities in both their native language and English, children's literacy levels at primary three level (Grade 3) have remained low in both the native language and English. The National Assessment of Progress in Education (NAPE) report (2011) indicated that the literacy levels of primary three children have remained low, particularly reading comprehension (Uganda National Examination Board, UNEB 2011). The NAPE report pointed out that the low levels of literacy were attributed to children's difficulties in comprehending what they read in standardised stories in either their native language or English. In addition, children experienced challenges in describing what they read in the standardised stories which were an indicator of reading comprehension difficulty. The findings are illustrated in Figure 1.

The UNEB (2011) asserts that children's reading comprehension difficulties are probably attributable to inappropriate instructional strategies employed by teachers when teaching reading. In addition, the UNESCO (2014) report on teachers' issues in Uganda pointed out that the reading comprehension difficulties among Uganda bilingual children could be attributed to teachers' lack of sufficient pedagogical skills and classroom practices.

These views imply that teachers' inappropriate instructional strategies of reading could be a major cause of reading comprehension challenges among bilingual children. Therefore, the researcher was compelled to investigate, design, adapt and implement a balanced reading instruction programme as an intervention to empower teachers with instructional strategies that could improve their instruction of reading comprehension in both the native language and English. The study was directed by the research question: how do teachers respond to the balanced reading instruction programme?

\section{Balanced reading instruction}

Balanced reading instruction is a comprehensive strategy whereby children are taught explicitly, systematically and consistently how to understand the structure of language, as well as construct meaning from different texts. In balanced reading instruction, children's phonemic awareness skills, decoding skills and comprehension skills are developed (Kelly 1997; Zygouris-Coe 2001). Balanced reading instruction comprises phonological awareness, alphabet knowledge, vocabulary knowledge and comprehension (Learning First Alliance 2000; Zygouris-Coe 2001).

Phonological awareness is concerned with the development of awareness of sounds of language. It involves identification and manipulation of sound structures in the spoken word of a particular language (Garton \& Pratt 1998; Joubert, Bester \& Meyer 2013). Children ought to learn the correspondences between the individual sounds of language, the phonemes and the letters that represent the sounds if they are to master the reading and writing processes (Garton \& Pratt 1998). Phonemic awareness is part of phonological awareness which is the ability to hear, identify and manipulate the individual sounds (phonemes) in spoken words and is linked directly to phonics which relates to letters they represent (Chou, Wang \& Ching 2012).

Alphabet knowledge is concerned with recognising and naming letters, both upper and lower case, and knowing the sounds they represent. Learners need to know the sounds that are associated with each letter or with groups of letters. They also need to know that sounds map onto the printed letters (Antonacci \& O'Callaghan 2004). Direct instruction of alphabet knowledge in the early grades has proven to prevent reading difficulties among children from diverse cultural and linguistic backgrounds (Foorman et al. 1998).

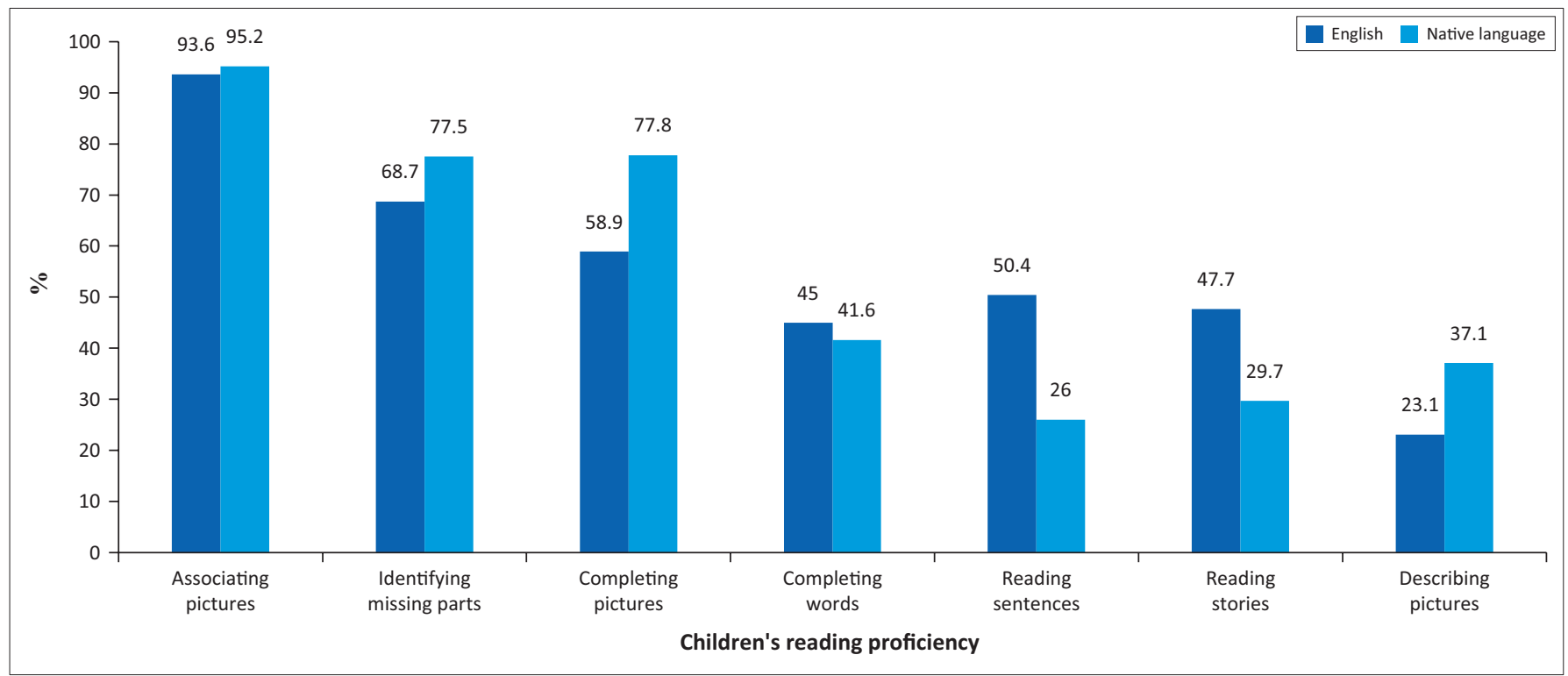

Source: National Assessment of Progress in Education Report (NAPE), 2011, The achievement of primary school pupils in Uganda in numeracy and oral reading, UNEB, Kampala FIGURE 1: Children's proficiency in reading comprehension in English and native language. 
Vocabulary knowledge encompasses understanding the breadth and the depth of vocabulary. The breadth of vocabulary refers to the number of words the reader knows, while the depth of vocabulary refers to the multiple presentations of known words (Proctor et al. 2009). Good vocabulary supports the development of reading comprehension, whereas too many unknown words in a given text disrupt reading for comprehension (Oakhill \& Cain 2004).

Comprehension is a process in which a reader chunks words into phrases and selectively recalls ideas in individual sentences, understands or infers relationships in terms of what is actually happening when a reader comprehends (Irwin 2007). Comprehension occurs at word, sentence and passage levels; children must decode and know the meaning of words in order to comprehend what they read (Manset-Williamson \& Nelson 2005). For children to read and comprehend a given text, they need to decode and recognise by sight the words in the text, understand the meaning of the words and sentences, relate the meaning of sentences to the text, activate and use prior knowledge to infer meaning and understanding and continually monitor their understanding of the text (Mc Naughton \& Mc Naughton 2012).

Harvey (2013) asserts that for primary school students to comprehend what they read, they need to engage in activities for vocabulary development with regard to word identification, decoding and comprehension. They should also be taught reading comprehension strategies such as predicting, visualising, making inferences, activating prior knowledge and summarising ideas in the text. Au (2006) argues that when teaching learners from diverse language backgrounds, teachers should use explicit instruction of comprehension strategies. This explicit instruction should include teacher-directed instruction, explicit explanation which involves telling students exactly what they are to learn and why, modelling or demonstrating how strategies are carried out, guided practice, independent application of strategies and rich literature experiences (Au 2006; MansetWilliamson \& Nelson 2005).

Torgesen (2005) contends that an intervention such as balanced reading instruction requires that teachers are welltrained and experienced in order to effectively implement the intervention measures incorporated in the programme. As teachers implement the balanced reading instruction, they should give intensive, explicit instruction on a daily basis for 20 to $45 \mathrm{~min}$ to enable children to make steady and significant progress in their reading comprehension (Pikulski 1997; Zygouris-Coe 2001). Wharton-Macdonald, Pressley and Mistretta (1998) point out that during the implementation of the balanced reading instruction, teachers need to make use of small, ability-group instruction. Small group instruction assists teachers to give learners opportunities for practice as well as receiving immediate feedback from them (Pikulski 1997). Torgesen (2005) asserts that researchers who design and implement an effective reading instruction intervention ought to take into consideration the need for well-trained and experienced teachers who are persistent in their efforts not to leave any child behind.

The above literature directed the design and implementation of the balanced reading instruction for this study. The researcher adapted and incorporated components of the balanced reading instruction and instructional strategies in the programme for the study. The strategies included phonics instruction, explicit instruction of reading comprehension on a daily basis, small group instruction, modelling, guided practice, teacher's modelling or scaffolding, literacy engagement and story book reading. Activities for sound recognition and vocabulary development were included in the programme for this study. Development and usage of materials such as cut-out letters from cardboard boxes and teacher-made texts were also incorporated in the programme. Through participatory action research (PAR) the study aimed to establish the effectiveness of the balanced reading instruction programme in equipping teachers with strategies that could enable them to improve their instruction of reading comprehension to bilingual children in both the native language (Runyankole) and English.

\section{Research design and methods}

This study used a critical qualitative research paradigm to investigate the balanced reading instruction programme for improving teachers' instruction of reading comprehension of bilingual children in the context of Uganda. Neuman (2003) asserts that critical qualitative researchers work in collaboration with participants primarily to reflect on and improve the phenomenon under study in its natural setting. This research paradigm aimed to obtain participants' views, opinions, behaviours and understanding of the phenomenon through the use of focus group interview discussions, direct observation and document data (Creswell 2014). In this study, teachers' instruction of reading comprehension in both Runyankole and English was the phenomenon addressed through the balanced reading instruction programme.

The critical qualitative approach enabled the researcher to understand teachers' instructional practices of reading comprehension in their natural settings which were the classroom context and the school. The approach made it possible for the researcher to work together with teacher participants to design, adapt, implement, reflect and evaluate the balanced reading instruction programme with regard to teachers' improvement of their instruction of reading comprehension in the native language (Runyankole) and English.

Participatory action research was employed in this study. This research is an interactive process with an actionreflection cycle. The researcher and the participants jointly identify the problem in their practice and plan, implement and reflect. Then they evaluate the action in 
order to improve their knowledge and practice (Eliana, Milenkiewicz \& Bucknam 2008).

The PAR action-reflection cycle process begins with identifying or diagnosing the problem, planning for change or action, acting and observing the processes and consequences of change, reflecting on these processes and consequences, re-planning, acting and observing again, reflecting again and evaluating (Kemmis \& McTaggart 2007; Mc Niff \& Whitehead 2002). As researchers engage themselves in the PAR cycles, they improve their knowledge and understanding and implement the change in accordance with data findings (Eliana et al. 2008). Pain, Whitman and Milledge (2007) assert that PAR as an action research is driven by: a democratic model in which people can produce, own and use knowledge, participants who have a stake in the phenomenon being researched, participants' collaboration and working together at every stage of research and resultoriented action or improvement.

The primary objective of PAR is to leave its participants motivated and energised in order to act on the modified change or improvement. This is done through involving participants in the study that enables them to improve on their practice. Researchers of PAR also focus on investigating the phenomenon under study within its natural setting, for instance the school or community (Eliana et al. 2008). Kemmis and Taggart (2007) state that the success of PAR is not whether the participants have faithfully followed the cycles but rather whether they have obtained a strong and authentic sense of development and progress or improvement in their practices.

With the PAR process in mind, the researcher worked in collaboration with the education officer, Mbarara Municipality and head teachers of primary schools and identified 'NKSP' (pseudonym) primary school where the native language (Runyankole) and English were taught to children of lower primary classes. As a result, the issues of teacher's instructional strategies of reading comprehension in both languages would be easily represented in this setting. In addition, the school was specifically selected as its children come from families of low economic status who engage in subsistence farming. It is therefore difficult for the parents in this school to adequately provide the conventional reading materials to their children, hence requiring inventive programmes to address reading comprehension gaps.

The teacher participants of this study were also from 'NKSP' primary school. Four Grade 3 teachers were purposively selected on the recommendation of the head teacher of the same school. The teachers were specifically chosen because they were teaching reading to children of primary three.
These teachers had also had experience in teaching reading to children of lower primary classes, and thus could understand and articulate the views and opinions on teaching reading comprehension in both the native language and English.

Forty Grade 3 children were also selected in this study as indirect participants because they were the children being taught by the four teachers. The researcher preferred to use primary three teachers with their children because it is in this class that teachers are expected to teach a variety of comprehension strategies to children. Thereafter children could use the strategies to comprehend texts in different story books as well as be able to read fluently (Antonacci \& O'Callaghan 2004).

The balanced reading instruction programme was implemented in relation to the action-reflection cyclic process of PAR for a period of 24 weeks. The first phase of PAR is identification of the problem (week one). During this phase the researcher made exploratory visits to the school as the study context. In these visits she sought permission from the head teacher to gain access to the school and the participants. The head teacher signed the consent form as evidence to allow the researcher to conduct the study in the school. The teachers also signed consent forms in agreement to participate in the study. Through the focus group interview session, the researcher in collaboration with the teacher participants sought to find out the specific challenges of reading comprehension among bilingual children. During the session, teachers' responses clearly brought out they had instructional gaps, in particular in teaching reading comprehension, as one of the major causes of reading comprehension challenges for bilingual children in this study.

The second phase of PAR (planning for change and action), which lasted for 1 week, dealt with designing the balanced reading instruction programme as an intervention. This programme was to address teachers' instruction gaps in the teaching of reading comprehension to bilingual children. In this phase, teachers and the researcher analysed and discussed in detail each of the components of the balanced reading instruction that the researcher explored from the literature. These components were: explicit instruction of phonological awareness, alphabet principle, vocabulary development and comprehension. They then discussed the strategies that would be incorporated in the programme to include: phonics instruction, guided reading practice, reading aloud, extensive reading practice, small group instruction, teacher modelling or scaffolding, literacy engagement and ongoing assessment (Chou et al. 2012; Kelly 1997; Zygouris-Coe 2001). Thereafter, the researcher and

TABLE 1: Biographical information of teacher participants.

\begin{tabular}{|c|c|c|c|c|}
\hline Participant & Gender & Qualifications & Teaching experience & Classes taught \\
\hline Teacher A & Female & Grade III Teacher's Certificate & 24 years & Primary 1-3 (lower primary classes) and Primary 4-6 (upper primary) \\
\hline Teacher B & Female & Grade III Teacher's Certificate & 6 years & Primary 1-3 (lower primary classes) \\
\hline Teacher C & Female & Grade III Teacher's Certificate & 6 years & Primary 1-3 (lower primary classes) \\
\hline Teacher D & Female & Grade III Teacher's Certificate & 10 years & Primary 1-3 (lower primary classes) \\
\hline
\end{tabular}


teacher participants adapted the components and strategies and designed the balanced reading instruction programme that the participants could use to improve their instruction of reading comprehension in both Runyankole and English.

The third phase of PAR (action and observe) involved explicit instruction using the adapted strategies and activities in the balanced reading instruction programme. The purpose of phase three was to utilise the content and strategies of the programme in the instruction of reading comprehension to bilingual children in the classroom context. Since teachers' responses in phase one of PAR indicated that they had gaps in the instruction of reading comprehension, it was decided that the researcher would conduct interactive professional development sessions. The participants participated in sessions that emphasised the explicit instruction of alphabet knowledge, phonological awareness instruction, vocabulary development instruction, comprehension instruction and the development of reading materials and activities.

The sessions were purposely conducted in order to equip teachers with strategies to teach the fundamentals of reading comprehension, as well as comprehension strategies. For instance, teachers obtained phonics instruction as a strategy to teach sounds of the alphabet and phonological awareness. In addition, they acquired the skills to make reading materials such as cut-out letter cards and syllables from strips of cardboard boxes obtained from the school surroundings as well as teacher-made texts. In the case of reading comprehension, the teacher participants attained the skill of inculcating comprehension strategies among children, as well as construction of carefully graded questions. After the interactive professional development sessions, it was acknowledged that intensive explicit instruction should be conducted in Runynkole before being introduced to English. This phase took a period of 21 weeks.

The teachers and researcher collaboratively decided to devote 15 weeks to the instruction of Runyankole as it was the medium of instruction and the first language of the participants. In addition, teachers' mastery of the instruction of reading comprehension in their first language would support them to effectively teach comprehension in English (Cummins 2005). In the period of 15 weeks teachers systematically carried out their instruction from the alphabet principle to comprehension in small groups of 10 children for $1 \mathrm{~h}$ on a daily basis (Chou et al. 2012; Torgesen 2005). In the last six weeks, teachers concentrated on teaching reading comprehension in English while using the same components and strategies of the programme.

The fourth phase of PAR dealt with the evaluation of the balanced reading instruction programme. Since the methodology of this PAR was critical qualitative in nature, in collaboration with the teacher participants, the researcher reflected on and evaluated the programme. This phase was done in the last week of the implementation of the programme. The purpose of the evaluation phase was to establish the effectiveness of the programme towards improving teachers' instruction of reading comprehension to bilingual children in both Runyankole and English. Data was collected at every phase of the implementation of the programme.

Focus group interviews were utilised to collect information from teacher participants. The sessions were guided by a focus group discussion guide that comprised open-ended questions (Krueger 2002). Focus group interviews are structured as small group interviews focusing mainly on interviewing people who are similar in some way and collecting information on a particular topic under study. Emphasis is put on respondents' insights, responses and opinions during the focus interview sessions (Program Development and Evaluation 2000). Krueger (2002) advances that the participants for focus group interviews should range from 5 to 10 people per group, carefully recruited and of similar type who can bring out in-depth information about a specific topic.

Patton (2002) states that focus group interviewing aims at gathering high-quality information in a social context where people can consider their own views in the context of the views of others on a specific research topic. He further advances that focus group interview sessions, if well conducted, have advantages that include: enhancing data quality through interactions among participants, quick assessment of a relatively consistent shared view of a great diversity of views, cost-effective data that is collected from a number of people at a specific time and enjoyment of sessions by participants.

Three focus group interviews were conducted with Grade 3 class teachers as participants of this study. The first session was conducted in the planning for change and action stage of the programme. The researcher led the session while guiding the teachers to focus on identifying the current strategies they use in teaching reading comprehension to bilingual children and their effects on children's reading comprehension. The outcomes of the focus interview session became the basis on which the researcher and the teacher participants discussed and adapted the balanced reading instruction programme.

The second focus group interview session was conducted in the action and observe cycle which dealt with the implementation of the planned strategies, materials and activities in the programme and its impact on the teachers' instruction of reading comprehension to bilingual children. The participants' views assisted the researcher to get feedback on the progress of the programme in improving teachers' instruction and its effects on children's reading comprehension. This interview session enabled the researcher to gather high-quality information from the participants in an interactive and relaxed context (Patton 2002). The discussion sessions were video recorded and then transcribed. 
The third group focus interview session was conducted in the evaluation cycle purposely to gather information on the effectiveness of the balanced reading instruction programme in empowering teachers with strategies for improving their instruction of reading comprehension in both the native language (Runyankole) and English. This is in agreement with Patton (2002) who states that a focus group interview is one of the strategies researchers could use to obtain participants' perceptions to evaluate the outcomes and impact of research projects.

Conducting focus group interviews could be a challenge to researchers in that time for a particular individual to respond can be restrained. Further, the number of questions asked could be restricted in the group setting. It is also likely that the individuals whose viewpoint is a minority perspective may not be inclined to speak up and risk negative reactions (Patton 2002). Therefore, to address these challenges in this study, the researcher played the role of a moderator and mediated the discussions. She made sure the discussions were not dominated by one or two participants. Each participant was given an opportunity to freely express their opinions on the question under discussion. The researcher also used four questions per group interview session discussion in order to provide time for the teachers to freely express their views, opinions and ideas (Krueger 2002; Patton 2002).

In addition to the data collected from the focus group interviews, the researcher observed a number of lessons in which the balanced reading instruction programmes was explicitly applied in the instruction of reading comprehension to children in their native language (Runyankole) and English. Kawulich (2005) defines observation as a systematic description of events, behaviours and artefacts in the social setting chosen for the study. Patton (2002) points out that observation as a date collection strategy assists researchers: to describe the study setting, the activities carried out and people and participants' perspectives on the study question. Opie (2004) points out that when using the observation strategy, the observer can either be a participant or a nonparticipant. In the case of observer as participant, there is interaction with those being observed but the observer does not take part in the activities in which they are engaged. A non-participant observer does not interact with those being observed.

In this study, the researcher was a participant observer as teachers taught different aspects of reading compression to children in Runyankole and English. While playing the role of the observer as a participant, she listened to interactions between the teachers and children as they explicitly utilised the strategies and activities in the programme. She also listened to children's responses as they participated in oral and written activities (Wajnryb 1992). In addition, the researcher wrote her observations as field notes in a reflective journal. The lessons she observed were videotaped. However, her activities during the observation (such as videotaping and taking notes as field notes) were made known to the class teachers and children. The observations of different lessons assisted the researcher to obtain first-hand information on teachers' participation in the teaching and learning context. Opie (2004) points out that observation can be challenged by observer interpretation, is time consuming and thus detrimental to researchers. In the case of this study, the lessons observed were videotaped in order to check against observer bias and misinterpretation.

Owen (2014) points out that document analysis deals with analysing documents in order to gather information on a particular subject under study. In this study, the documents from which information was gathered about the effectiveness of the balanced reading instruction programme for teachers included lesson plan books, children's activity books and assessment sheets. Teachers' lesson plans were analysed in order to obtain feedback on their preparations and usage of strategies and activities as planned in the different phases of the balanced reading instruction programme. Analysis of children's activity books and assessment sheets provided data on feedback about teachers' instruction of the aspects of reading comprehension.

Data from the documents was used to corroborate data from observation and focus group interviews in order to increase the credibility of the findings (Bowen 2009; Owen 2014). Bowen (2009) further asserts that documents can be an effective strategy to collect data when events can no longer be observed or the respondents have forgotten the details of the events. In this study, document analysis was used to triangulate data collected through observation, focus group interviews and the researcher's reflective journal. In so doing, potential biases that could have arisen from using one data collection strategy were decreased, which increased the credibility of the study (Bowen 2009).

Nonetheless, document analysis can be a challenge to the researcher in terms of being time consuming when the documents are collected, reviewed and analysed (Bowen 2009). In this study, the researcher addressed this challenge by working in collaboration with teachers and identified ways of keeping and maintaining children's activity books and assessment sheets throughout the period of 24 weeks for the study. This assisted the researcher and teacher participants to track the children's feedback in regard to teachers' improvement in their instruction of reading comprehension in both Runyankole and English. For instance, children's assessment records were filed and kept by teachers. Children's activity books were kept by teachers in the teachers' cupboards and were distributed to children at the time of the lessons and thereafter collected. These methods thus made it easier for the teachers to retrieve and collect the documents at the end of the study.

Data was also collected using a researcher's reflective journal. The data collected in the reflective journal included the researcher's reflections on the entire process of the 
implementation of the balanced reading instruction programme. It also contained notes on reflective sessions held at different phases of the programme. In these reflective sessions the researcher and teacher participants shared their views on strategies well utilised in the instruction, challenges faced and how they were dealt with by adapting the programme and how the strategies assisted children to improve their reading comprehension. Lesson observations were also written in the researcher's reflective journal under the heading of field notes. The reflective journal assisted the researcher to reflect on her actions and experiences as data during the analysis phase of this study. It also provided the researcher with an opportunity to reflect on what was occurring in the study. Further, the journal enabled the researcher to keep record of decisions and issues that were particularly important in tracing the progress of teacher empowerment and children's reading comprehension (Chou et al. 2012; Department of Economics and Social Affairs 2006). This data were analysed and enabled the findings of the study to be presented with minimal researcher bias (Anney 2014).

Data were analysed through content analysis and inductive strategies. Content analysis was used to analyse videotaped data of focus group interviews, lesson observations and data analysed from documents (Maryring 2000). Content analysis units were used to identify and group data into similar patterns across interviews, lesson observations and data from documents.

Inductive analysis was used to establish recurring similar ideas, opinions, and responses across all data from focus groups interviews, lesson observations, documents and the reflective journal. Similar groups of data were then integrated and categorised into themes and sub-themes (Creswell 2007). The data analysis was done in accordance with the research topic, question and methodology of the study.

\section{Ethical consideration}

Ethics clearance was obtained from the University of Pretoria before the commencement of data collection in the field. Thereafter, permission was sought from the principal education officer, Mbarara Municipality and the head teacher of the primary school ('NKSP') in order to gain access to the school, teachers and children. Creswell (2014) points out that for researchers to obtain approval of authority to access the study sites and participants, they need to write letters specifying the purpose of research, duration and its outcomes. The researcher prepared the letters of permission for the education officer and the head teacher and the informed consent forms for the participants (the teachers of primary three classes) well in advance for approval by the Faculty of Education Ethics Committee of the University of Pretoria (EC 15/11/04).

\section{Findings and discussions}

The aim of this study was to establish the effectiveness of a balanced reading instruction programme at empowering teachers through PAR with strategies they could use to improve their instruction of reading comprehension to bilingual children. The implementation of the programme was conducted in four phases in relation to the cyclic process of the PAR of this study.

The second phase dealt with the conceptualisation of the programme (planning for change or action). In the conceptualisation process the researcher in collaboration with the teachers identified and discussed the components and activities of the programme. They further discussed, incorporated and adapted instructional strategies to use in the implementation of the programme. However, the findings from the teachers' responses indicated fears of uncertainty about using the methods of the programme. In regard to their uncertainties regarding strategies, without any provocation, Participant TA/1 A said: 'Teaching sounds is a challenge in both the local language (Runyankole) and English because we attained few strategies to teach them'. In agreement with this participant, Participants TB/2, TC/3 and TD/4D further explained:

'Teaching is not a challenge in sounds but also in other areas such as blending of sounds, vocabulary, and reading comprehension in both Runyankole and English.' (TB/2, TC/3 and TD/4D, females, teachers)

In regard to the few strategies attained, all the participants reported that they lacked prior training to effectively teach aspects such as sounds, vocabulary development and reading comprehension in Runyankole and English. They particularly pointed out that they needed a programme that could help them to teach children to understand what they read. For instance, Participant TA/1 had this to say:

'If we could get ways of teaching correct letter sounds, formulation of words, and reading comprehension in both Runyankole and English, then we will benefit from this programme. Even the parents of our children are complaining that our children do not read.' (TA/ 1 , female, teacher)

Teachers' responses highlighted that the balanced reading instruction programme was paramount in equipping them with strategies to teach the prerequisites of reading comprehension, as well as reading comprehension strategies. Thus, the researcher, in agreement with the participants, conducted interactive professional development sessions before the actual implementation of the programme.

The third phase (action and observe) of the programme focused on the implementation of the reading instruction programme. In this phase, the teacher participants were trained in the teaching of sounds, vocabulary development and reading comprehension. This was done through interactive professional development sessions. Thereafter they conducted explicit instruction in reading comprehension, first in Runyankole and then in English in the classroom context. The findings indicated that teachers' participation in the programme assisted them to attain strategies such as phonics instruction to teach the alphabet of Runyankole and 
English, as well as blending of sounds to formulate words. For instance, in unison all the teachers said:

'Aaah!!! Hati nitumanya entaniso eriahagati yalifu y'orunyankole n'oruzungu. [Aaah!!! We have known the difference between the alphabet and their corresponding sounds of Runyankole and English].' (TA/1, TB/2, TC/3 and TD/4, females, teachers [author's own translation])

They further explained that:

'We can also assist our children to formulate words using vowels and syllables such as o-mu-ti; e-mpa-ngo; sl-ee-p; c-o-mb.' (TA $/ 1, \mathrm{~TB} / 2, \mathrm{TC} / 3$ and TD/4, females, teachers)

This implies that they would not mix the sounds of Runyankole and English when teaching letter-sound recognition.

With regard to teaching comprehension the teachers' responses indicated that they ably taught reading comprehension in both Runyankole and English. For instance, Participant TA/1 said:

'I can ably teach reading comprehension in both Runyankole and English but more especially in Runyankole. My children answered the questions on the story while writing in full sentences. I need to help them to do more practice in reading books individually and set questions on the stories for them to answer.' (TA/1, female, teacher)

The fourth phase (evaluation) focused on the balanced reading instruction programme. In this phase the researcher in collaboration with the teacher participants sought to find out whether the programme had made an improvement to teachers' instruction of reading comprehension to bilingual children. Teachers' responses revealed that strategies such as phonics instruction, cut-out letters, individual reading of texts and story books and the formulation of carefully graded questions improved their instruction. In responding the strategies used in their instruction Participant TB/2 said:

'Before the programme, we were teaching while mixing sentences and words. We did not know to teach sounds. We would begin with teaching sentences to children, yet the children did not know the sounds. But now, I have learnt the systematic way of teaching reading that is from sounds to syllables, then to words and sentences and finally to reading stories and texts.' (TB/2, female, teacher)

\section{Participant TC/3 also responded:}

'We have learnt the systematic way of teaching reading comprehension which is good!' (TC/3, female, teacher)

The findings also indicated that participants gained skills in the formulating of questions that provoked children to comprehend what they read. For example, Participant TC/3 also responded:

'Formulating questions about the story. My children can use the story and answer the questions very well. For example, Ahabwaki Nyina Kengoro nanabisa akanake [Why is the mother of Kengorois bathing her baby?] This type of question enables me to guide children to gain a deeper understanding of the importance of bathing children.' (TC/3, female, teacher [author's own translation])

With regard to teachers' participation in the programme, the findings revealed that the teacher participants acknowledged that they attained confidence and love to teach reading comprehension in Runyankole as well as English. For instance, Participant TD/4 said (raising her arms, very happy, stressing her confidence):

'Thank you Madam. I take this opportunity to thank you!!! Since this programme started, I feel confident that I can firmly teach reading comprehension even if I am transferred to another school.' (TD/4, female, teacher)

\section{Participant TA/1 added:}

'At the beginning of this project, I had a lot of fear that the strategies we trained in this programme were not similar to those we have been using to teach reading comprehension. So, I saw these strategies new to me. But now we can use them to teach very well.' (TA/1, female, teacher)

In summary, the findings of the study indicate that the strategies teachers used before the programme were not appropriate in the instruction of reading comprehension. Thus, teachers' participation in the programme enabled them to obtain new strategies that enhanced reading comprehension among bilingual children.

\section{Conclusion}

The findings of the study answered the question of how teachers respond to the balanced reading instruction programme. Through their participation in the programme, the teachers attained new strategies of teaching sounds, vocabulary and reading comprehension in both Runyankole and English. The study also revealed that the strategies the teachers used before their participation in the programme were ineffective in enhancing reading comprehension among bilingual children. Teachers' self-esteem and positive attitude towards teaching reading comprehension in both Runyankole and English was pointed out as a result of participation in the programme.

This study therefore makes a contribution to teachers' instruction of reading comprehension in the native language to countries such as Uganda whose emphasis is placed on using the native language as a medium of instruction in children's primary education. It also makes a contribution to teachers' instruction with regard to strategies they could utilise to address children's reading comprehension first in the native language and then in English.

The study was qualitative in nature, as well as PAR in nature. It focused on Grade 3 teachers in one single school as a study context. The findings therefore cannot be generalised to all Grade 3 teachers in Mbarara Municipality primary schools and all other teachers of Grade 3 in other geographical contexts in Uganda. Thus, this study could be 
used to provide a researched-based programme for improving teachers' instruction of reading comprehension to bilingual children.

This study recommends that research should be carried out on the instruction of reading in both the native languages and English nationwide in order to identify the challenges teachers experience in the instruction of reading comprehension and point to the government to provide appropriate intervention programmes. A largescale intervention should be conducted for improving teachers' instruction of reading comprehension in the native language of bilingual children.

\section{Acknowledgements}

I would like to acknowledge Prof. Ina Joubert and Prof. Nkidi Phatudi for their constructive criticisms and guidance while carrying out my study.

\section{Competing interests}

The author declares that no competing interest exist.

\section{Author's contributions}

I declare that I am the sole author of this research article.

\section{Funding}

This research received no specific grant from any funding agency in the public, commercial, or not-for-profit sectors.

\section{Data availability statement}

Data sharing is not applicable to this article as no new data were created or analysed in this study.

\section{Disclaimer}

The views and opinions expressed in this article are those of the author and do not necessarily reflect the official policy or position of any affiliated agency of the author.

\section{References}

Anney, V.N., 2014, 'Ensuring the quality of the findings of qualitative research looking at trustworthiness criteria', Journal of Emerging Trends in Educational Research and Policy 5(2), 272-281.

Antonacci, A. \& O'Callaghan, C.M., 2004, Portraits of literacy development, instruction and assessment in a well-balanced program $k-3$, Pearson Education Inc., Old Tappen, NJ.

$\mathrm{Au}, \mathrm{K} . \mathrm{H} ., 2006$, Multicultural issues and literacy achievement, literacy teaching series, Eribaum Associates Inc., Mahwah, NJ.

Barrat-Pugh, C. \& Rohl, M., 2000, Literacy learning in the early years, Allen and Unwin, Crows Nest.

Bowen, G.A., 2009, 'Document analysis as a qualitative research method', Qualitative Research Journal 9(2), 27-40. https://doi.org/10.3316/QRJ0902027

Cummins, J., 2005, Teaching for cross-language transfer for dual language education, possibilities and pitfalls, Teachers of English to Speakers of Other Languages (TESOL), Alexandria.

Chou, C.P., Wang, S. \& Ching, G.S., 2012, 'Balanced reading instructions, an action research on elementary cram school students', International Journal of Research Studies in Language Learning 1(1), 3-20. https://doi.org/10.5861/ijrsll.2012. v1i1.7
Creswell, J.W., 2007, Qualitative inquiry and research design, choosing among five approaches, 2 nd edn., Sage Publications, Thousand Oaks, CA.

Creswell, J.W., 2014, Research design, qualitative and mixed methods approaches, 4th edn., Sage Publications, New Delhi.

Department of Economics and Social Affairs, 2006, Guidelines for review and appraisa of the Madrid international plan of action on ageing, United Nations, New York.

Eliana, F., Milenkiewicz, M.T. \& Buckman, A., 2008, Participatory action research for educational leadership, using data-driven decision making to improve schools, Sage Publications, Thousand Oaks, CA.

Foorman, B.R., Fletcher, J.M., Francis, D.J. \& Schatschneider, C., 1998, 'The role of instruction in learning to read, preventing failure at risk children', Journal of Educational Research 90(1), 37-55. https://doi.org/10.1037/0022-0663. 90.1.37

Garton, A. \& Pratt, C., 1998, Learning to become literate, the development of spoken and written language, 2nd edn., Blackwell Publishers, Oxford.

Harvey, M., 2013, Reading comprehension, strategies for elementary and secondary students, viewed 01 February 2018, from http://www.lynchburg.edu/wp-content/ upload/volume8-2013/HarveyM-readingcomprehension.

Irwin, J.W., 2007, Teaching reading comprehension processes, 3rd edn., Pearson Education Inc., Boston, MA.

Joubert, I., Bester, M. \& Meyer, E., 2013. Literacy in the foundation phase, 2nd edn., Van Schaik Publications, Hatfield.

Kawulich, B.B., 2005, 'Participant observation as data collection', Qualitative Socia Research 16(13), viewed 26 September 2014, from http://www.qualitativeresearch.net

Kelly, H., 1997, How children learnt to derive meaning from text, Eric Document Reproduction Service, (Eric Reproduction Service Number ED416459).

Kemmis, S. \& Mc Taggart, R., 2007, Participatory action research, communication and public sphere, viewed 20 July 2015, from http://www.citeer.ist.psu.edu/view/ documents/download?doi=10.1.473759

Krueger, R.A., 2002, Designing and conducting focus group interviews, viewed n.d., from https://www.eiu.edu/ihec/Krueger-FocusGrouplnterviews.pdf

Learning First Alliance, 2000, 9 Components of effective research supported reading instruction, viewed 04 February 2018, from https://www.readingrockets.org/ article/9-components-effective-research-supported-reading-instruction

Manset-Williamson, C, \& Nelson, J.M., 2005, 'Balanced strategic reading instruction for upper-elementary school students with reading disabilities, a comparative study of two approaches', Learning Disability 28(2), 59-74. https://doi. org/10.2307/4126973

Maryring, P., 2000, 'Qualitative content analysis', Qualitative Social Research 1(1), $1-7$.

McNaughton, J. \& McNaughton, D., 2012, Literacy instruction for individuals with autism, cerebral palsy, down syndrome and other individuals, viewed 01 February 2018, from http:///www.accileracy.psu.edu/index.php/page/show/ February

McNiff, J. \& Whitehead, J., 2002, Action research principles and practice, 2nd edn., RoutledgeFalmer Taylor and Francis Group, New York.

National Assessment of Progress in Education Report (NAPE), 2011, The achievement of primary school pupils in Uganda in numeracy and oral reading, UNEB, Kampala.

National Curriculum Development Centre (NCDC), 2007, National primary schoo curriculum for Uganda (primary two), NCDC, Kampala.

Neuman, W.L., 2003, Social methods, qualitative and quantitative approaches, 5 th edn., Pearson Education Inc., Boston, MA.

Oakhill, J.V. \& Cain, K., 2004, 'The development of comprehension skills', in T. Nunes \& P. Bryant (ed.), Handbook of children's literacy, pp.155-180, Kluwer Academic Publishers, London.

Opie, C., 2004, Doing educational research, a guide to first time researchers, Sage Publications, London.

Owen, G.T., 2014, 'Qualitative methods in higher education policy analysis, using interviews and document analysis', The Qualitative Report 19(52), 27-40, viewed 23 March 2018, from http://www.nova.edu/ssss/QR/QR19/owen52.pdf

Pain, R., Whitman, G. \& Milledge, D., 2007, Participatory action research toolkit, an introduction to using PAR as an approach to learning, research and action, viewed July 2015, from http://www.dur.ac.uk/resources/beacon/PARtoolkit.pdf

Patton, M.Q., 2002, Qualitative research and evaluation methods, 3rd edn., Sage Publications, Thousand Oaks, CA.

Pikulski, J.J., 1997, Preventing reading problems, factors to successful early intervention programs, viewed 26 February 2015, from http://www.eduplace. $\mathrm{com} / \mathrm{rdg} / \mathrm{res} /$ prevent.html.

Proctor, P., Uccelli, P., Dalton, B. \& Snow, C.E., 2009, 'Understanding depth of vocabulary online with bilingual and monolingual children', Reading and Writing Research Quarterly 25(4), 311-333. https://doi.org/10.1080/10573560903123502

Program Development and Evaluation, 2000, Quick tips, focus group interviews, viewed 22 January 2016, from http://www.uwex.edu/ces/pdande.

Torgesen, J.K., 2005, A principle guide to intensive reading interventions for struggling readers in reading first schools, National center for reading first technical assistance, viewed 26 February 2015, from http://www. ReadingFirstSupport.us

Uganda National Examination Board (UNEB), 2011, The achievement of primary school pupils in Uganda in numeracy and oral reading, UNEB, Kampala. 
United Nations Scientific and Cultural Organisation (UNESCO), 2014, Teacher initiative in sub-Saharan Africa, Teacher issues in Uganda, a shared vision for an effective teacher policy, UNESCO IIP, Pole De Dakar.

Uganda Government, 1992, Education for national integration and development white paper, Marianum Press, Kampala.

Wajnryb, R., 1992, Classroom observation tasks, a resource book for language teachers and trainers, Cambridge University Press, Cambridge.
Wharton-Macdonald, R. Pressley, M. \& Mistretta, J., 1998, 'Outstanding literacy instruction in first grade classrooms, teacher characteristics and students' achievements', Elementary School Journal 99, 101-128. https://doi.org/10.1086/ 461918

Zygouris-Coe, V., 2001, Balanced reading instruction in K-3 classrooms, Florida literacy and reading center, University of Florida, viewed 26 February 2015, from http:// flare.ucf.edu 